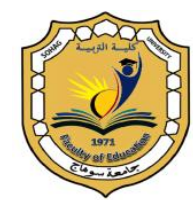

كلية التربية

جامعة سوهاج

المجلة الثربوية

\title{
المهارسات الإبداعية أهداف منشودة وضرورة تربوية في تعليم اللغة العربية
}

\section{إعداد}

أ.د / محمود هلال عبدالباسط عبدالقادر

أستاذ المناهج وطرق تدريس اللغة العربية

كلية التربية - جامعة سوهاج

جامعة الملك خالد - المملكة العربية السعودية

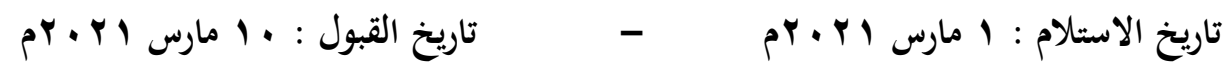


ملخص:

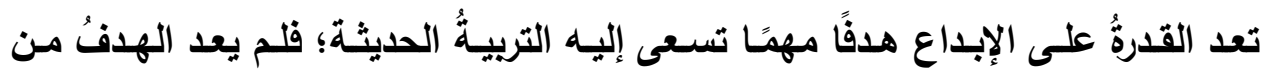

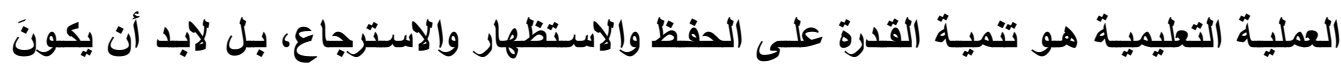

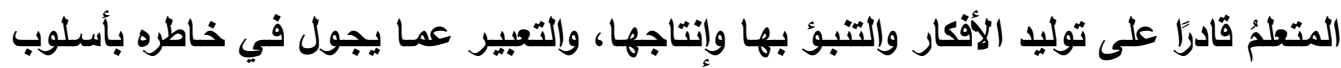

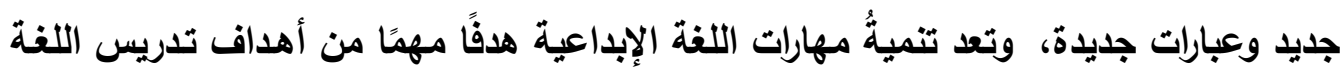

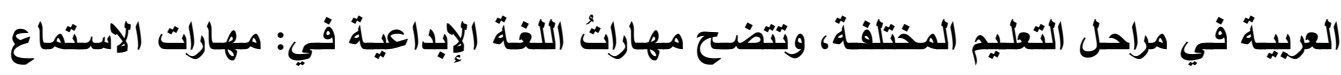

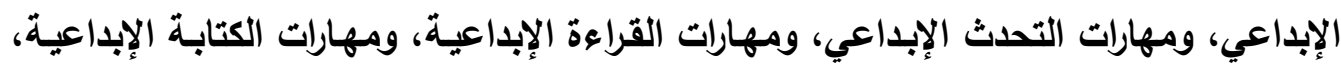

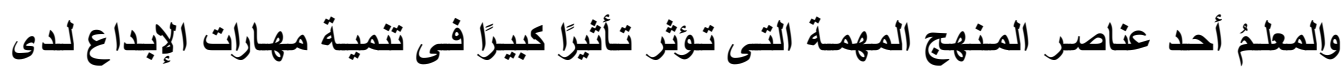

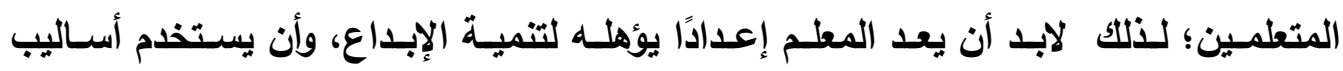

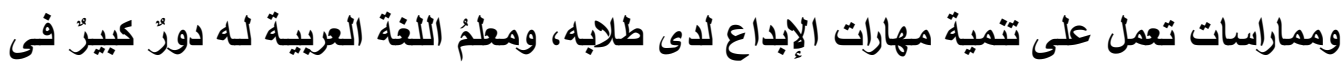

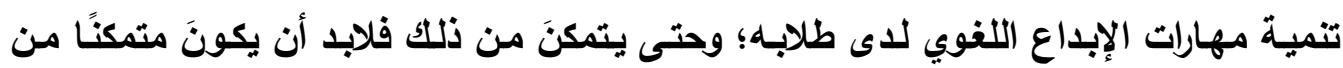

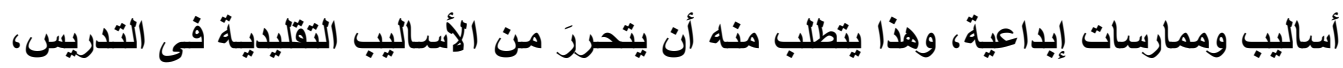

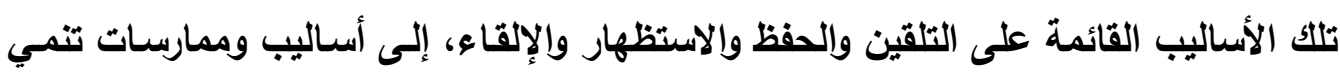
التفكير والمشاركة والتفاعل والنقد والإبداع والإنتاج لاى المتعلم.

الكلمات المفتاحية: الممارسات الإبداعية-أهداف منشودة-- ضرورة تريوية- تعليم اللغة العربية 
من أهم أهداف تدريس اللغة العربية تنمية مهارات اللغة المختلفة: الاستماع والتحدث والقراءة والكتابة؛ وتتكامل هذه المهارات جميعًا؛ لتحقيق الأهداف المرجوة من تعليم وتطلم اللغة العربية فى مختلف المراحل التطليمية، ويعد دور المطلم فى تنمية مهارات اللغة

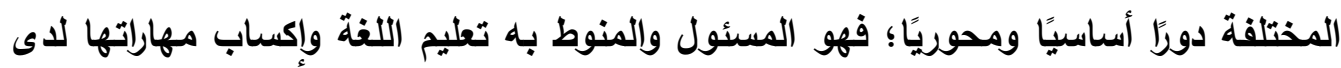

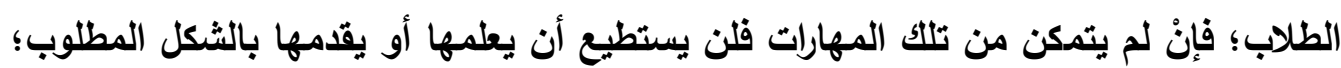

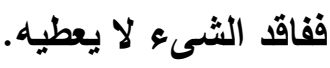
وتعد القدرة على الإبداع هدفًا مههًا تسعى إليه التربية الحديثة؛ فلم يعد الهدفُ من

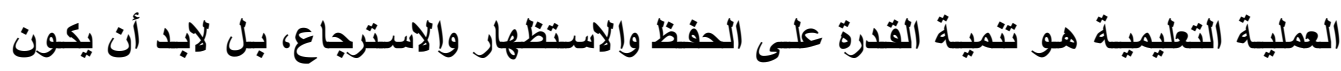

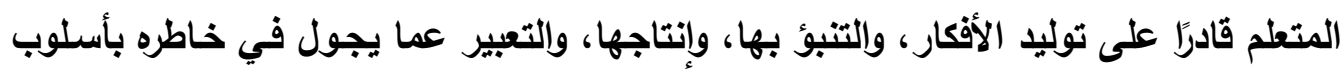
جليد وعبارات جليدة. وتعد تتمية مهارات اللغة الإبداعية هدفًا مهمًا من أهداف تدريس اللغة العربية في

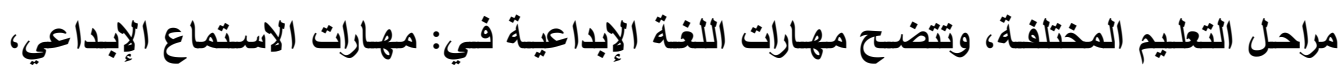

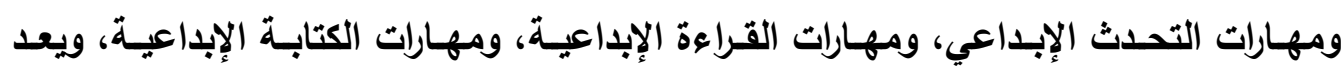
الجانب الإبداعي هو المستوى الأعلى في فنون ومهارات اللغة العربية؛ لذلك ينبغي التركيز

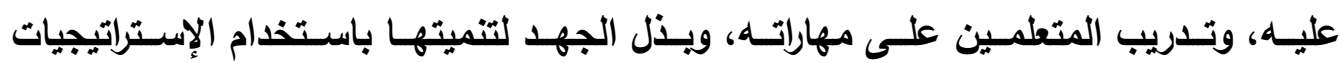
والأساليب والممارسات المناسبة لها.

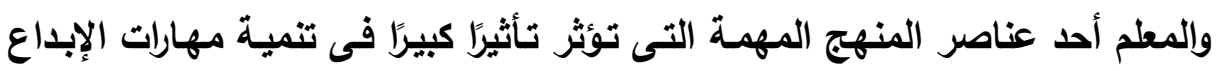

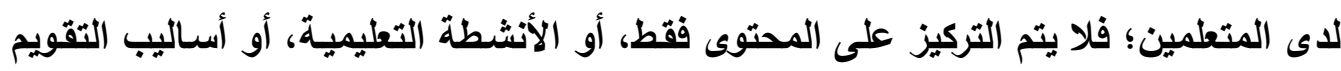

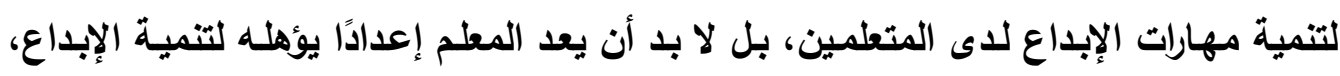

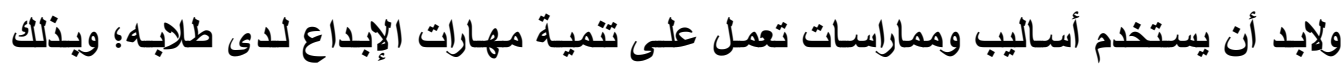
تكتمل منظومة المنهج القائم على الإبداع.

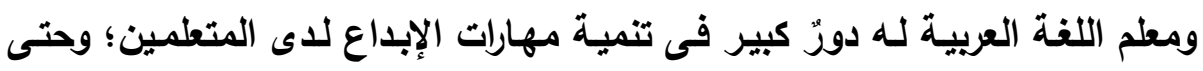

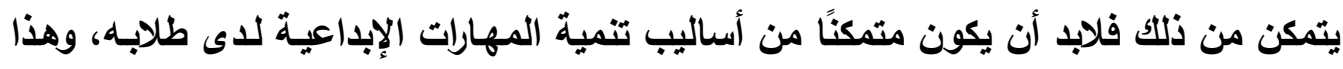

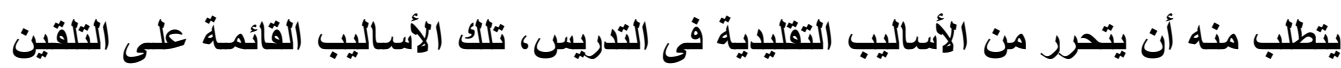


والعفظ والاستظهار والإلقاء، إلى أساليب تعتمد على التفكير والمشـاركة والتفاعل والإنتاج من قبل المتعلمين.

وإعداد المتعلم المباع مرتبط بنوع التعليم الذى يتلقاه، وطبيعة ومكونات هذا التعليم،

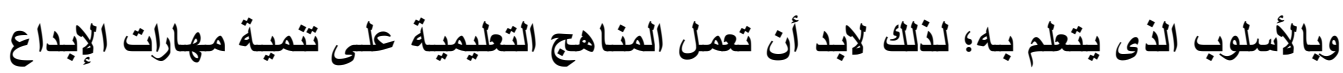

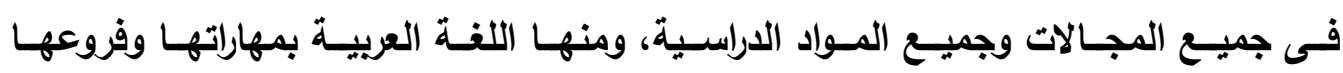

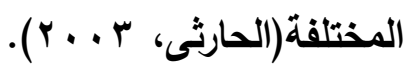

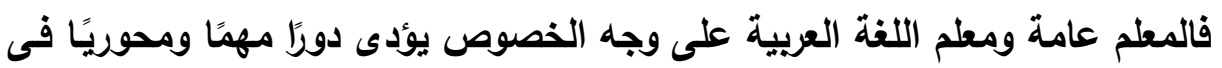

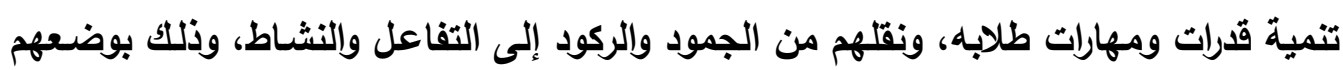

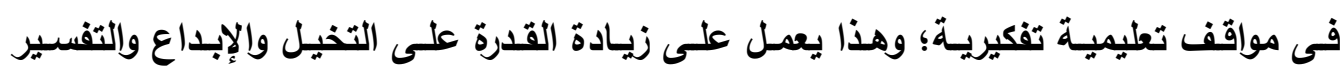

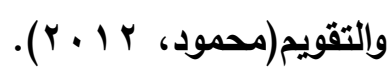

وتعليم مهارات اللغة وقواعدها وفنونها يحتاج- أيضًا - إلى أسـاليب تريويـة حديثة

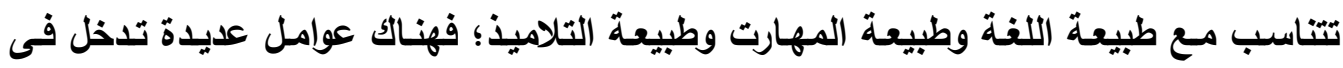

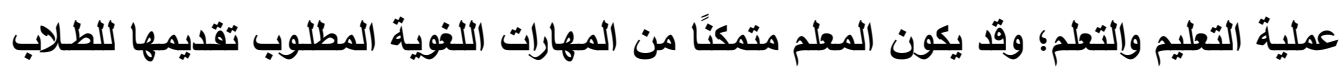

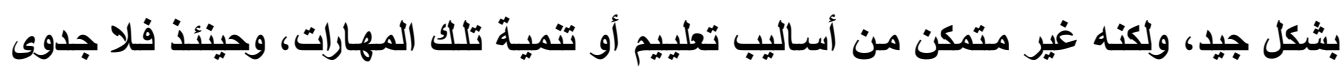

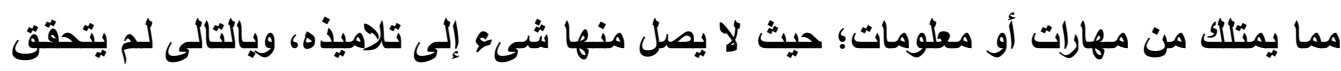

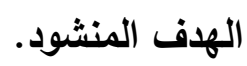

والإبداع بصفة عامـة ومهارات التدريس الإبداعي بصفة خاصـة تحتـاج إلى مواقف

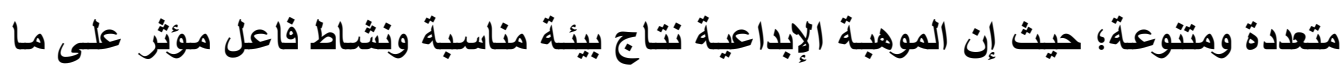
يمتلكه الفرد من قدرات إبداعية، كما أن التفكير الإبداعي تفكير مفتوح لا تحده المعلومـات الإبهات التقليدية؛ فهو يعبر عن نفسه في صورة إنتاج هادف يتسم بالتنوع والجدة والأصالة والقابلية للتحقيق، فلا يوجد إبداع بدون الحوار والتفاعل والمناقشـة، ونبذ التلقين والحفظ والاستظهار

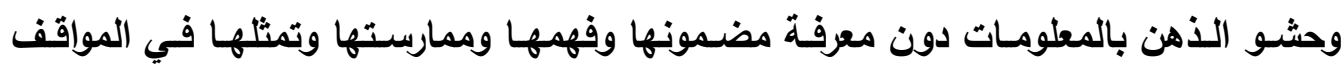

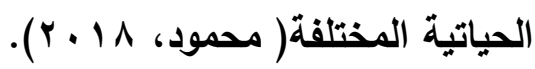

فالبحث عن أسـاليب تربوية حديثة ومناسبة لتنمية مهارات اللفة العربية الإبداعية

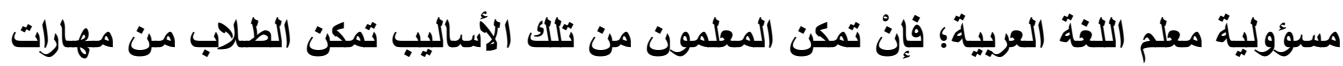


الإبداع، لأن معلم اللفة العربية عليه دور كبير فى تنمية مهارات الإبداع فى مجالات اللغة

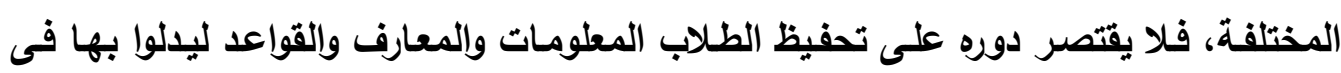

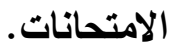

ويحتاج التدريس الإبداعى من المعلمين التمكن من أساليب مثيرة للتفكير، والقدرة على توليد الأفكار، ووحل المشكلات، والبحث عن تفسيرات والبحث عن حلول جديدة، كما

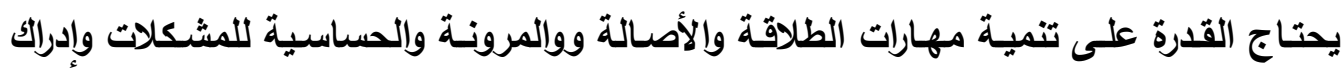

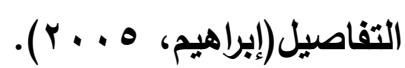

فالتمكن من أساليب التدريس الإبداعى من المتطلبات الضرورية التى تهدف إليها

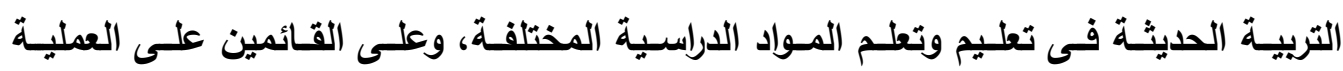

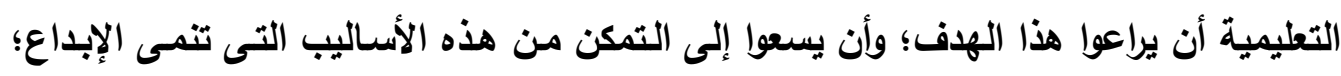

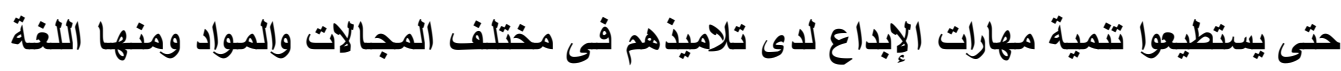

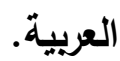

وسوف نعرض فيما يلي أهم الممارسات الإبداعية الخاصة بالمتعلم في مهارات

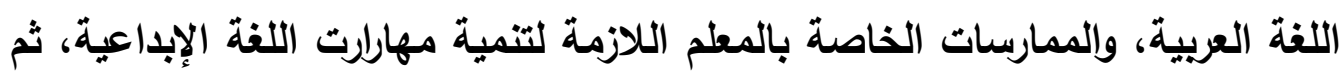
نختم بأهم التوصيات المقترحة لتنمية مهارات اللغة الإبداعية: أوتًا: ممارسات المتعلم الخاصة بمهارات التحلدث الإبلداعي؛ للتحدث الإبداعي ممارسات ومهارات يمكن إبرازها فيما يلي:

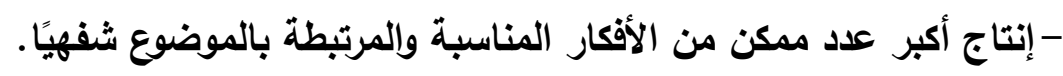

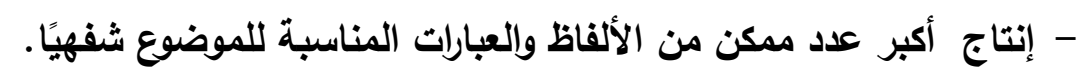
- إنتاج أكبر عدد ممكن من الصور والتعبيرات المجازية المناسبة للموضوع الكئل شفهيًا.

- إنتاج أكبر عدد ممكن من الأساليب المعبرة عن الموضوع شفهيًا.

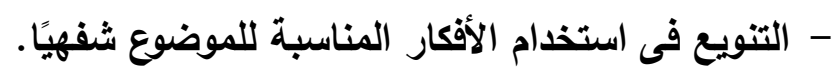
- استخدام صور وتعبيرات مجازية متنوعة شفهيًا. 
- التنويع فى استخدام الأساليب حسب ما يقتضى الموضوع شفهيًا. - سهولة الانتقال بين الأفكار بمنطقية، مع الريط بينها شفهيًا. - ذكر أفكار جليدة وقليلة الثيوع شفهيًا. - ذكر صور وتعبيرات مجازية جديدة ومتميزة شفهيًا. - استخدام ألفاظ جديدة حسب المضمون والفكرة شفهيًا. - استخدام أساليب جديدة وفريدة وقليلة الشيوع شفهيًا. - نطق أكبر عدد من الكلمات نطقًا سلسمًا شفهيًا. - التتويع فى نبرات الصوت وتتغيمه حسب حال المستمعين شفهيًا. - تسلسل الأفكار وترابطها وتنوعها شفهيًا. - التعبير عن الموضوع بجمل جليدة ومناسبة شفهيًا. - تمثيل الانفعالات المتضمنة أثناء التحدث، والقدرة على التنغيم.

\section{ثانيًا : ممارسات المعلم اللازمة لتنمية مهارات التحلثث الإبلداعي:}

لتتمية مهارات التحلث الإبداعى ممارسات، يككن أن يقوم بها المعلم أهمها ما يلي: - تثجيع الطلاب على الإنتاج الثفهي لأكبر عدد ممكن من الأفكار المناسبة والمرتبطة بالموضوع.

- إثارة الطلاب للإنتاج الثفهي لأكبر عدد ممكن من الألفاظ والعبارات المناسبة لـ للموضوع.

- تثجيع الطلاب للإنتاج الثفهي أكبر عدد ممكن من الصور والتعبيرات المجازية المناسبة للموضوع. - توجيه الطلاب للإنتاج الثفهي لأكبر عدد ممكن من الأساليب المعبرة عن

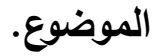
- تدريب الطلاب على التنويع فى استخام الأفكار المناسبة للموضوع شفهيًا. - تثجيع الطلاب لاستخدام صور وتعبيرات مجازية متنوعة شفهيًا.

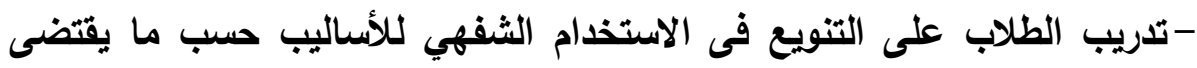

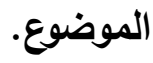


- دعوة الطلاب للانتقال بين الأفكار شفهيًا بمنطقية وسهولة مع الربط بينها. - تشجيع الطلاب على ذكر أفكار جليدة وقليلة الثيوع. - إثارة الطلاب لذكر صور وتعبيرات مجازية جديدة ومتميزة. - دعوة الطلاب لاستخدام ألفاظ جديدة حسب المضمون والفكرة. - تكليف الطلاب لاستخدام أساليب جديدة وفريدة وقليلة الثيوع شفهيًا. - تشجيع الطلاب على نطق أكبر عدد من الكلمات نطقًا سلسمًا. - تدريب الطلاب على التنويع فى نبرات الصوت وتتغيمه حسب حال المستمعين. - دعوة الطلاب لعرض أفكار متسلسلة ومترابطة ومتتوعة شفهيًا. - دعوة الطلاب للتعبير شفهيًا عن الموضوع بجمل جديدة ومناسبة. - تثجيع الطلاب على تمثيل الانفعالات المتضمنة أثناء التحدث، والقدرة على بلى التنغيم.

\section{ثالثًا: ممارسيات المتعلم الخاصة بمهارات الاستماع الإِلداعي:}

للاستماع الإبداعي ممارسات ومهارات يمكن توضيحها فيما يلي:

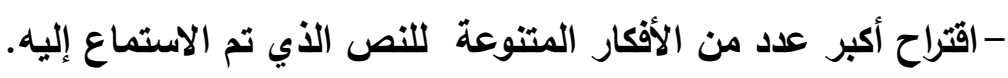
- اقتراح حلول جديدة لمشكلات وردت في النص الاستماعي. - التنبؤ بالأحداث للقصة المستمع إليها. - توقع نهاية لقصة ما لم ترد في النص الاستماعي. - تحويل النص لشكل آخر كالمسرحية والتمثيليه وغيرها. - اقتراح عناوين بديلة للنص الاستماعي. - وضع مقترحات جليدة ومتنوعة لتطوير النص الاستماعي. - تقديم صياغة جديدة للنص المستمع إليه كالرسم والتخطيط وإلكتابة. -طرح أسئلة والبحث عن إجابات لها من خلادة لهال النص الاستماعي. -توظيف النص الاستماعي فى علاج مشكلة وردت فى النص، أو مشكلة حياتية. - إعادة صياغة النص الاستماعي بطريقة جليدة. - ذكر أكبر عدد من الصفات لشخصيات وردت فى النص الاستماعي. 
- تلخيص النص بأسلوب المستمع. - إنتاج فكر جديدة مرتبطة بالنص الاستماعي. - استخلاص المعانى الضمنية من النص الاستماعي. باعي.

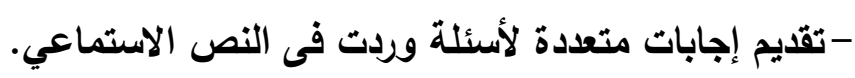

\section{رابعًا : ممارسيات المعلم الرلازمة لتنمية مهـارات الاستماع الإبلداعي:}

لتنمية مهارات الاستماع الإبداعي ممارسات، يمكن أن يقوم بها المعلم أهمها ما يلي:

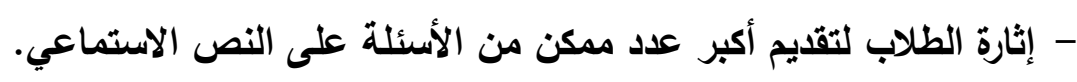
- تثجيع الطلاب على اقتراح أكبر عدد من الأفكار على النص الاستماعي. - توجيه أسئلة للطلاب تتطلب إنتاج أكبر عدد ممكن من الإجابات عن أسئلة في النص الاستماعي.

-تدريب الطلاب على إنتاج أكبر عدد من الحلول لمشكلة فى النص الاستماعي.

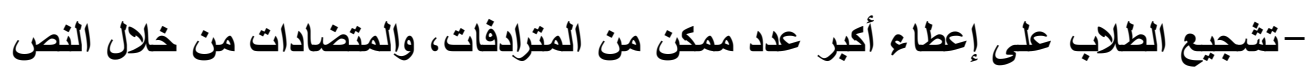
الاستماعي.

- تشجيع الطلاب على إنتاج فِكر متنوعة على النص الاستماعي.

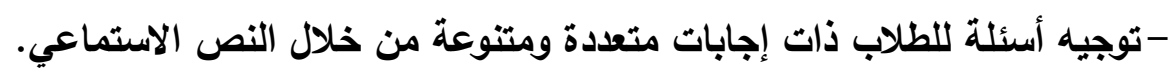
- تشجيع الطلاب على تقديم تعليلات ومبررات متنوعة حول ما ورد فى النص الاستماعي.

- تكليف الطلاب بإعادة ترتيب أفكار النص الاستماعي مرة أخرى ويشكل آخر. - تشجيع الطلاب على اقتراح عناوين متنوعة ومختلفة على النص الاستماعي. - تكليف الطلاب بتلخيص النص الاستماعي بأسلويهم. - تحفيز الطلاب على تقديم تفسيرات حول ما ورد في النص الاستماعي. -دعوة الطلاب إلى توقع نهاية للنص الاستماعي من خلال الأحداث. - تشجيع الطلاب على التنبؤ بالأحداث من خلال مقدمات من النص الاستماعي. - دعوة الطلاب إلى التعبير عن مواقف وردت فى النص الاستماعي بأسلويهم. 


\section{خامسًا : ممارسات التتعلم الخاصة بمهارات القراوة الإبلداعبة:}

للقراءة الإبداعية ممارسات ومهارات يمكن تنميتها لاى المتطمين فى مراحل التطليم

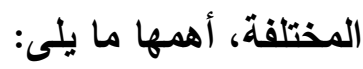
- اقتراح أكبر عدد ممكن من الكلمات والأفكار من النص القرائى. - اقتراح حلول جليدة لمشكلات وردت فى موضوع أو قصة. - التتبؤ للأحاثاث أو حبكة للموضوع، أو القصة قبل فيل نهايتها. - توقع نهاية لقصة ما لم يحدد الكاتب نهاية لها. - تحويل النص لثكل آخر كالمسرحية والتمثيليه. - اقتراح عناوين بديلة للنص القرائى. - وضع مقترحات جليدة ومتنوعة لتطوير النص. - تقديم حلول مبتكرة لنفس المشكلات الواردة فى النص. - تقديم صياغة جديدة للنص كالرسم والتخطيط والكتابة. - طرح أسئلة والبحث عن إجابات لها. - توظيف النص المقروء فى علاج مشكلة وردت فى النص، أو مشكلة حياتية. - إعادة صياغة النص القرائى بطريقة جديدة. - ذكر أكبر عدد من الصفات لثخصيات وردت فى النص أو القصة. - تلخيص النص بأسلوب القارىء.

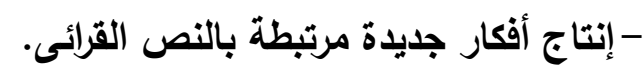

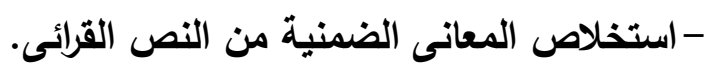
- تقديم إجابات متعددة لأسئلة وردت فى النص الفئل القرائى.

\section{سادسًا : ممارسات المعلم اليلازمة لتنمية مهارات القراوة الإبلداعية:}

لتنمية مهارات القراءة الإبداعية ممارسات، يمكن أن يقوم بها المعلم أهمها ما يلي: - إثارة التلاميذ لتقيم أكبر عداد ممكن من الأسئلة على النص القابل القرائي. - تثجيع التلاميذ على اقتراح أكبر عدد من الأفكار على النص القرائي. 
- توجيه أسئلة للتلاميذ تتطلب إنتاج أكبر عدد ممكن من الإجابات لأسئلة وردت في النص المقروء.

- تدريب التّلاميذ على إنتاج أكبر عدد من الحلول لمشكلة فى النص القرائي.

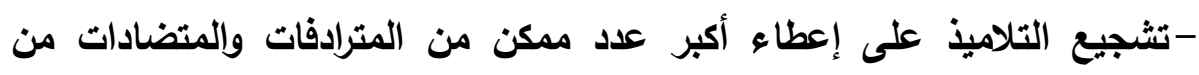

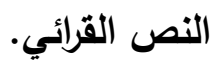

- تثجيع التلاميذ على إنتاج فِكر متنوعة على النص القرائى.

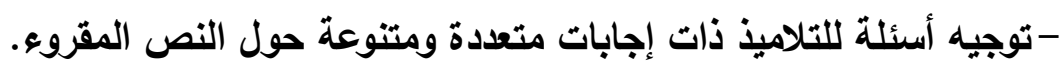

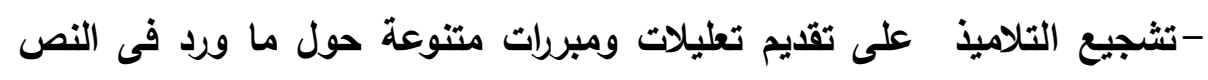
المقروء.

- تكليف التلاميذ بإعادة ترتيب أفكار النص القرائي مرة أخرى ويثكل آخر. - تثنجيع التلاميذ على اقتراح عناوين متنوعة ومختلفة على النص القرائي. - تكليف التلاميذ بتلخيص النص القرائس بأسلويهر.

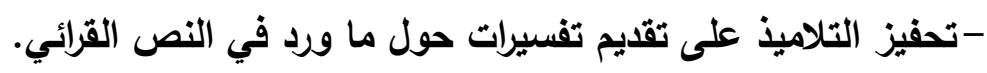
- دعوة التلاميذ إلى توقع نهاية للنص القرائى من خلال الأحاث التأل التاردة فيه. - تثجيع التلاميذ على التتبؤ بالأحاث من خلال مقدمات من النص القرائي.

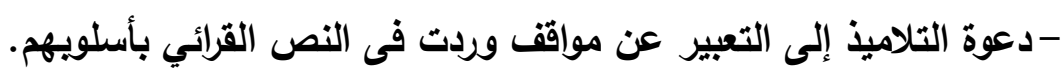

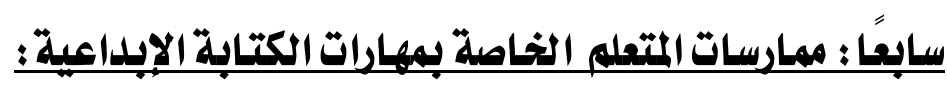
للكتابة الإبداعية ممارسات ومهارات، ويمكن توضيح هذه المهارات فيما يلي: - القدرة على اقتراح أكبر عدد ممكن من العناوين للنص الكتابي. - القدرة على ترتيب أفكار النص الكتابي ترتييًا منطقيًا ومتسلسلًا. - القدرة على اقتراح عناوين متعددة ومتنوعة للنص المراد الكتابة فيه.

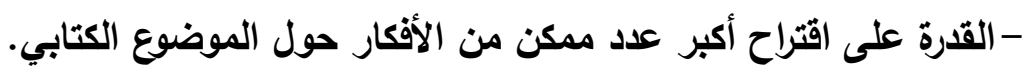

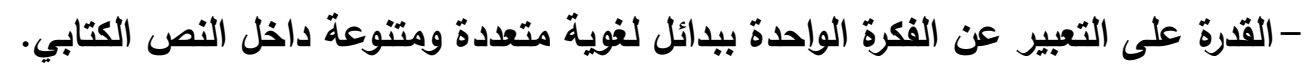

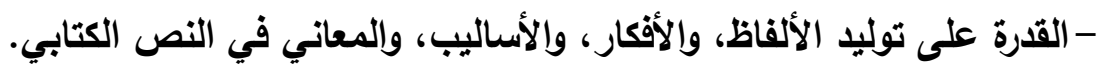
- القدرة على طرح أكبر عدد ممكن من الأسئلة حول الموضوع الكتابي. 
- القدرة على مراعاة تنظيم الوحدات الفكرية، وتماسك السياق داخل النص الكتابي. - القدرة على الانتقال من فكرة إلى أخرى بسهولة، وترابط خلال النص الكتابي. - القدرة على التعبير عن الفكرة الواحدة بجمل متنوعة ومختلفة. - القدرة على تدعيم أفكار النص الكتابي بالأدلة والثواهد والأمثلة المتنوعة.

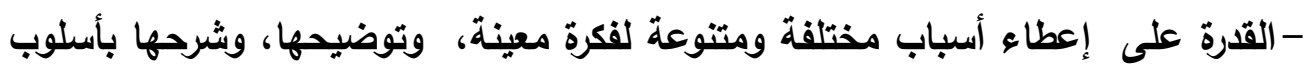
الكاتب.

- القدرة على كتابة مقدمة شيقة وجذابة؛ تمهـ للموضوع المراد الكتابة عنه.

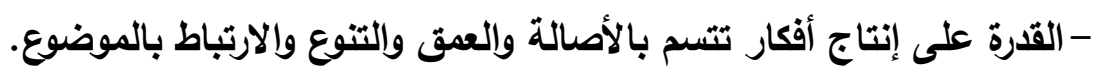
- القدرة على استخدام التراكيب اللغوية الشائعة فى سياقات جديدة ومختلفة، ويأسلوب الكاتب.

- القدرة على إعطاء أفكار جديدة، وغير مألوفة حول موضوع الكتابة. - القدرة على إبداء الرأى فى سلوك، أو موقف معين بأسلوب جليد من خلاعلاعل الكتابة. - القدرة على استخدام تراكيب لغوية جديدة؛ لتوضيح الفكرة في النص الكتابي. - القدرة على توسيع الفكرة الواحدة في النص الكتابي من خلال عدد من الأفكار والمعانى. - القدرة على إضافة أفكار جديدة ومتنوعة لفكرة رئيسة ومحورية. -القدرة على وصف قيمة إنسانية معينة بدقة من خلال ألفاظ يصوغها الكاتب فى تركيب لغوى.

\section{ثامنًا: ممارسيات المعلم اللازمة لتنمية مهارات الكتابة الإبلداعية:}

لتنمية مهارات الكتابة الإبداعية ممارسات، يمكن أن يقوم بها المعلم أهمها ما يلي :

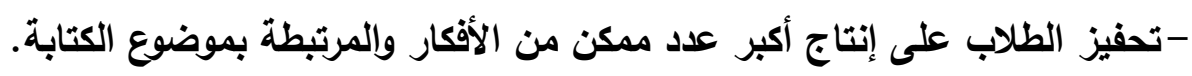
- تشجيع الطلاب على إنتاج أكبر عدد ممكن من الألفاظ والعبارات المناسبة لموضوع الكتابة.

- إثارة الطلاب لإنتاج أكبر عدد ممكن من الصور والتعبيرات المجازية المناسبة لموضوع الكتابة. - توجيه الطلاب لإنتاج أكبر عدد ممكن من الأساليب المعبرة عن موضوع الكتابة 
- تدريب الطلاب على التنويع فى استخام الأفكار المناسبة لموضوع الكتابة.

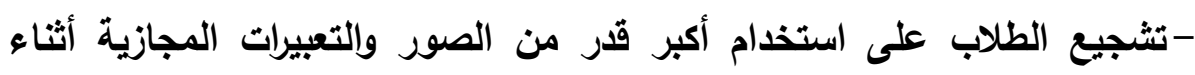
الكتابة.

- تدريب الطلاب على التنويع فى استخدام الأساليب حسب ما يقتضى موضوع الكتابة.

- دعوة الطلاب للانتقال بين الأفكار بمنطقية وسهولة، مع الريط بينها أثناء

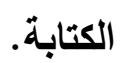

- تثجيع الطلاب على كتابة أفكار جليدة وقليلة الثيوع والتكرار بين زملائه

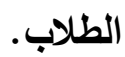

- إثارة الطلاب لكتابة صور وأساليب وتعبيرات مجازية جديدة ومتميزة.

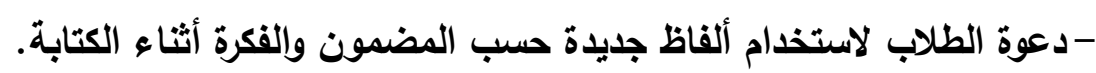
- تكليف الطلاب لاستخدام أساليب جديدة وفريدة وقليلة الثيوع بين زملائهم أثناء الكتابة.

- تثجيع الطلاب على كتابة أكبر عدد من الألفاظ الكلمات أثناء الكتابة الإبداعية. - دعوة الطلاب لعرض أفكار متسلسلة ومترابطة ومتنوعة أثناء الكتابة حول الموضوع الإبداعي.

-دعوة الطلاب للتعبير كتابيًا عن الموضوع الإبداعي بجمل جديدة ومناسبة ومرتبطة بالموضوع.

\section{تاسعًا : أهم التوصيات المقتز حة لتنمية مهارات اللفة الإبلداعية:}

يمكن تقديم بعض التوصيات لتنمية مهارات اللغة الإبداعية، أهمها ما يلي: - عقد دورات تدريبية لمعلمي اللغة العربية تركز على المماراسات الإبداعية فى تنمية مهارات

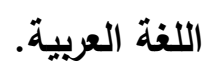

-الاهتمام بالأساليب والإستراتيجيات الإبداعية فى تنمية مهارات اللغة العربية فى مختلف

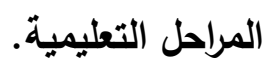
- الاهتمام بتنمية مهارات الإبداع اللغوي لاى المتعلمين فى مختلف المراحل التعليمية. 
- التركيز على الأساليب والإستراتيجيات الإبداعية المناسبة لكل مهارة من مهارات وفنون اللغة العربية. - الاهتمام بالتنمية المهنية لمعلمي اللغة العربية؛ لمواكبة الأساليب الحديثة في تعليم اللغة العربية.

- الربط بين الأسلوب التدريسى والمهارات اللغوية؛ حتى تتناسب أساليب التدريس مع مهارات اللغة. - ابتعاد معلمي اللغة العربية عن الأساليب التلقينية القائمة على الحفظ والاستظهار، والاتجاه نحو الأساليب التي تركز على الفهم والنقد والإبداع. - الاستفادة من الدورات التدريبية التي تركز على الأساليب والإستراتيجيات الحديثة فى تنمية مهارات الإبداع.

- الاهتمام بالمستوى الإبداعي في تتمية مهارات اللغة العربية بمختلف المراحل التعليمية. 


\section{المراجع}

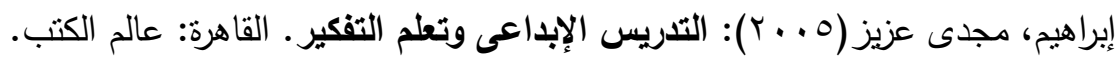

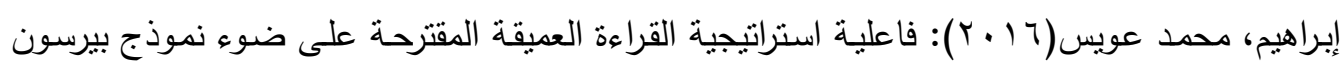

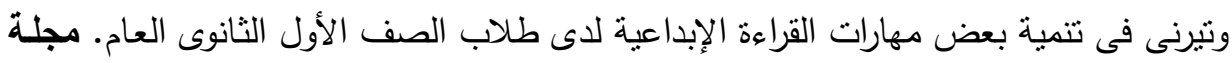

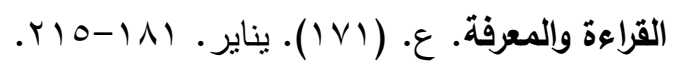

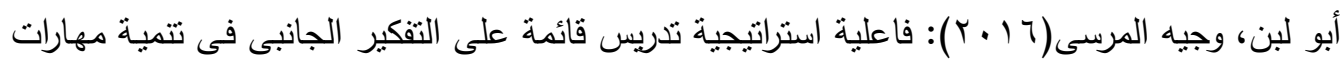

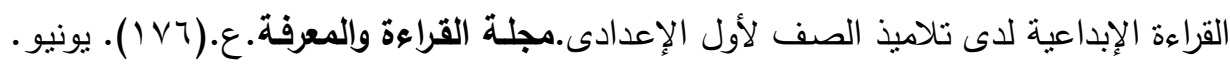

$$
. V \cdot-r \text {. }
$$

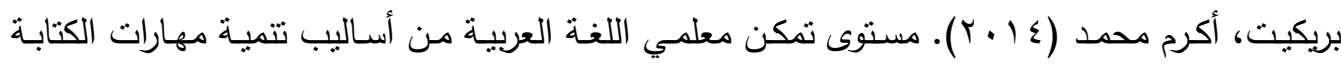

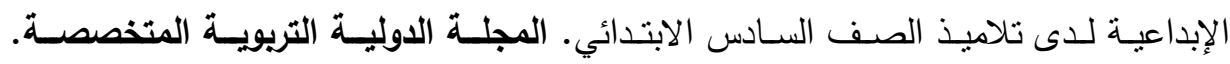

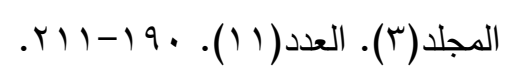

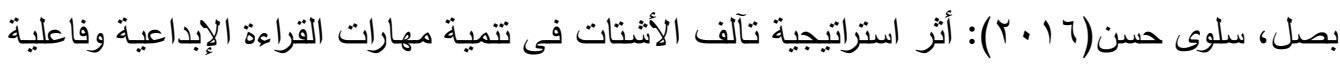

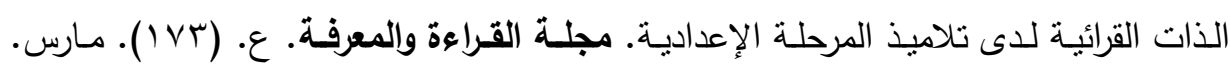

$$
.1 \% 7-v 9
$$

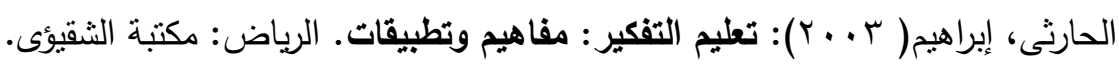

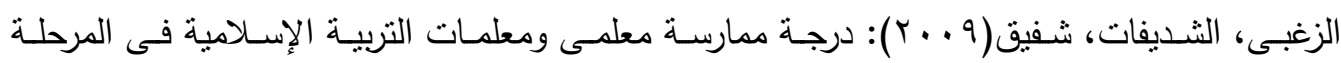
الثانوية لأساليب تثجيع التفكير الإبداعى فى محافظة المفرق بالأردن من وجهة نظرهم. مجلة دانة

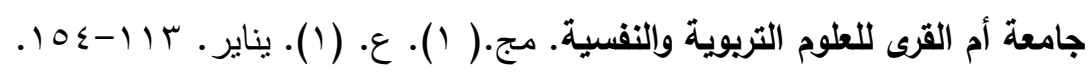

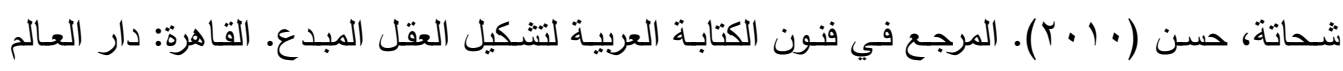

$$
\text { العربي. }
$$

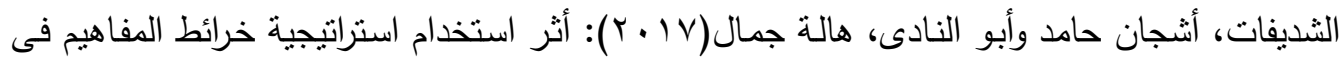
تتمية مهارات الفهم القرائى الإبداعى لدى تلاديذ الصف السادي الهاد الابتدائى فى المملكة العربية

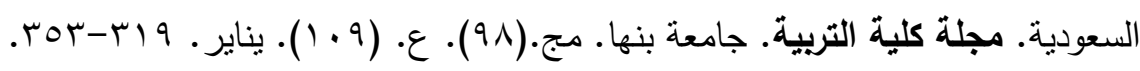

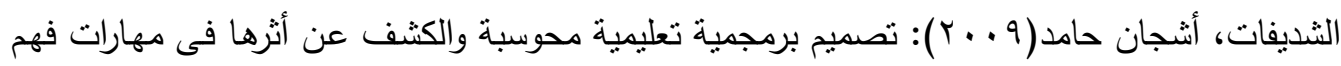
المسموع وفهم المقروء بالمستوى الإبداعى لدى طلبة الصف الثنالث الأساسى فى الأردن.رسالة

$$
\text { دكتوراه. كلية التربية. جامعة اليرموك. الأردن. }
$$


الظنحانى، محمد عبيد(V V • Y): أنشطة لغوبـة مقترحة لتطوير مهارات القراءة الإبداعيـة بمنهج اللغـة العربية للصف السابع بدولة الإمارات العربية المتحدة. مجلة كلية التربية بأسيوط. مـج.(rr).

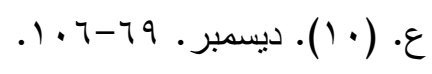

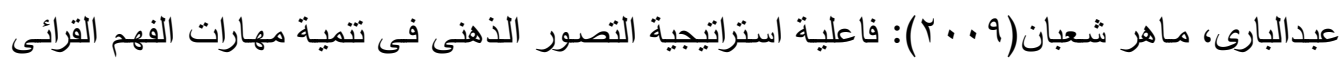
لتلاميذ المرحلة الإعداديـة. دراسـات فى المنـاهج وطرق التدريس. الجمعية المصرية للمناهج

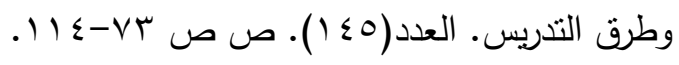

عبدالقادر، عبدالرازق مختار؛ اسـماعيل، عبدالرحيم فتحي (0 ( ب). مهارات الأداء اللغوي الإبداعي

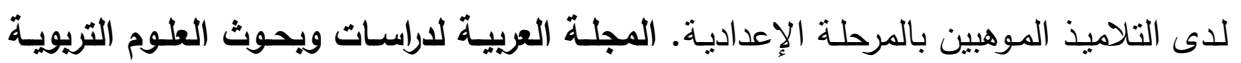

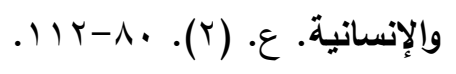

عبدالقادر ، محمود هـل(0 1 • ب). استخدام المدخل المعرفى الأكاديمى لتعلم اللغة فى تدريس القراءة وأثره فـى تنميـة مهارات الفهم القرائسى الإبـداعى والتواصل اللغوى للدى تلاميذ الصف الثانى

$$
\text { الإعدادى. المجلة التريوية. كلية التربية. جامعة سوهاج. ع. (و ب). يناير • }
$$

عبداللاه، ميمي عبدالرازق (T ( • (Y). فعالية برنامج قائم على التعليم المتمايز لتتمية بعض مهارات التقكير الناقد والكتابة الإبداعية لدى طلاب المرحلة الثانوية. رسالة دكتوراه. كلية التربية

$$
\text { بقنا. جامعة جنوب الوادي. }
$$

عبداللاه، نايل يوسف (0 . . r): فعالية بعض استراتيجيات عملية القراءة لتتمية مهارات الفهم الإبداعى والوعى اللغوى لدى طلاب الصف الأول الثانوى. المؤتمر الدولى الرابع. التعليم باللغة العربية

$$
\text { فى مجتمع المعرفة. معهد الدراسات التربوية. جامعة القاهرة. }
$$

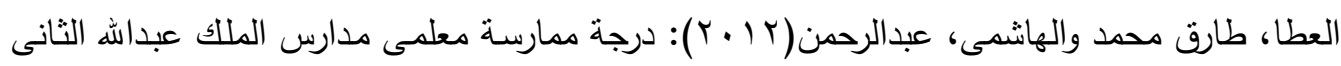
للتميز لمهارات التدريس الإبداعى. رسالة ماجستير . كلية العلوم التربوية والنفسية. جامعة عمان

$$
\text { العربية. الأردن. }
$$

عفانة،إلهام راتب والوائلى، سعاد عبدالكريم(T ( • r): درجة ممارسة معلمى اللغة العربية لمهارات القراءة الإبداعية وعلاقتها بالتفكير فوق المعرفى لدى طلبة الصف السابع الأساسى فى الأردن. رسالة

$$
\text { ماجستير • كلية الدراسات العليا. الجامعة الهاشمية. الأردن. }
$$

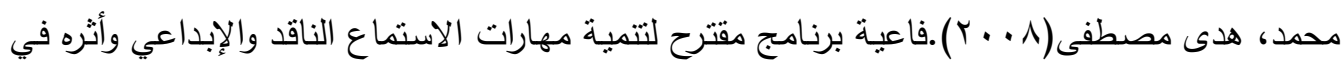
مهارات اتخاذ القرار لدى الطالبات المعلمات بشعبة رياض الأطفال. مجلة القراءة والمعرفة.

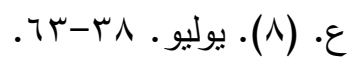




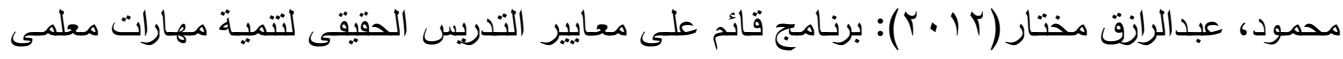

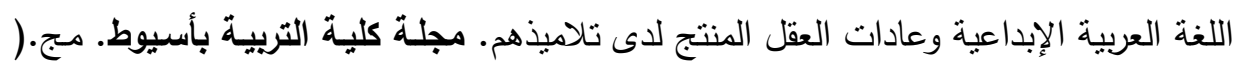

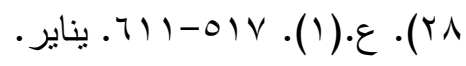

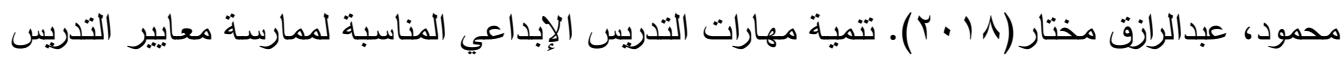

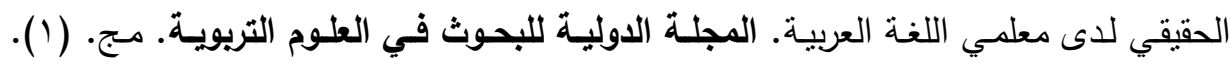

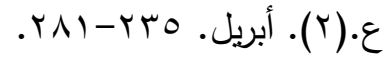

محمود، عبدالرازق مختار ؛ محمد، عبدالرحيم فتحي(10 • ب). فاعلية نموذج سكامبر في تتمية مهارات التحدث الإبداعي لدى التلاميذ الموهبين بالمرحلة الإعدادية. المجلة الدولية للأبحاث التريوية.

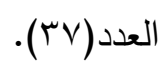

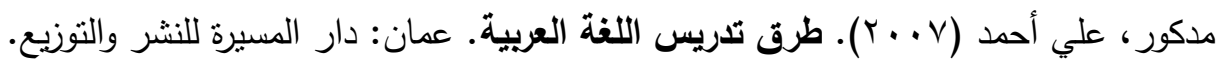

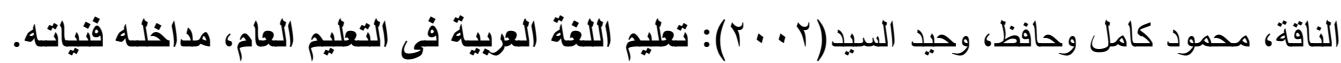
الجزء الأول. بنها: مطبعة الجامعة. 